Boise State University

ScholarWorks

CGISS Publications and Presentations

Center for Geophysical Investigation of the

Shallow Subsurface (CGISS)

1999

Use of Engineering Geophysics in the Design of Highway Passing

Lanes

P. Michaels

Boise State University

This is an author-produced, peer-reviewed version of this article. The final, definitive version of this document can be found online at Geotechnical Special Publication No. 113, published by the American Society of Civil Engineers.

Copyright restrictions may apply. doi: 10.4133/1.2922604 


\title{
USE OF ENGINEERING GEOPHYSICS IN THE DESIGN OF HIGHWAY PASSING LANES
}

\author{
P. Michaels, PE \\ Center for Geophysical Investigation of the Shallow Subsurface \\ Boise State University \\ 1910 University Drive \\ Boise, Idaho 83725 \\ pm@cgiss.boisestate.edu
}

\begin{abstract}
The addition of passing lanes has been a long standing need on Idaho Route 55. This narrow, winding road is one of the few routes that links Boise, Idaho, with destinations to the north. The roadway is bounded by a steep rising slope on the east, and a precipitous drop to the Payette River on the west. Additionally, the area is known for landslide hazards. Given these hazards and uncertainties in the subsurface geology, Idaho Transportation Department (ITD) commissioned an engineering geophysical survey to aid in the design of the passing lanes just south of Banks, Idaho.

The engineering design required that several issues be addressed. These included the following:

1. Slope Stability

2. Amount of blasting required.

3. Need for retaining walls.

4. Volumes of soil and rock to be excavated.

To help design engineers address these questions, P-wave refraction mapping was used to produce cross-sections perpendicular to the roadway. A novel approach was needed, since traditional in-line shooting would have required offsets greater than were available. The solution was to perform a 3-D, ground consistent, delay-time inversion. Soil and rock properties, and variations in the thickness of overburden were determined. These results were found to be in agreement with track-hoe trenching done at selected locations along the roadway.

The geophysical work revealed that the site differed significantly from assumptions used in the initial design stages of the project. The potential for landslides was found to be significant. Given the updated geologic picture and projected costs, ITD decided to abandon this site for the passing lanes. The project was terminated, thus avoiding excessive costs that would have been experienced due to the differing site conditions.
\end{abstract}

\section{INTRODUCTION \\ Differing Site Conditions and Risk}

Knowledge of the soil profile is essential to the engineering design of projects like roadways, tunnels, and foundations. A major risk for such projects is that the subsurface geology will differ from the assumptions made in the initial design and cost estimation stages of the project. Such miscalculations due to Differing Site Conditions (DSC) can be costly. For example, in the case of an earthen dam project, Green Construction Co. v. Kansas Power and Light Co., unexpected soil moisture content cost Green $\$ 420,000$ (Steigler, 1994a). In the case of a 3.3 mile road project, Brown Bros. v. Metropolitan Government, "unclassified excavation" involved excavation of rock instead of soil. Brown sought $\$ 281,541$ as a cost overrun, but lost in 
This is an author-produced, peer-reviewed version of this article. The final, definitive version of this document can be found online at Geotechnical Special Publication No. 113, published by the American Society of Civil Engineers. Copyright restrictions may apply. doi: 10.4133/1.2922604

court (Steigler, 1994b). The cost of a 3 mile geophysical survey might easily be viewed as a bargain in hindsight.

The burden of these additional costs can fall on several parties, including owners, engineering design firms, and construction contractors. For that reason, the inclusion of a DSC clause in contracts is becoming common. To further reduce risk, subsurface data are also appearing in contracts. In most cases, one should go beyond presenting raw data. A growing practice is to include a Geotechnical Baseline Report (GBR) as an addition to contract documents (Austin, 1994). Engineering geophysics should be considered as a cost effective means to reduce the exposure of responsible parties to financial risk. When used in conjunction with test borings, trenching and soil testing, the combined knowledge and resulting geologic picture can be used to avoid costly mistakes, and provide the information needed for better designs.

In the case of the Banks passing lane proposal, significant uncertainty existed about the soil profile. Initial field observations of surface geology revealed a soil profile consisting of a poorly compacted, silty sand overburden with shallow granitic bedrock below. Adding passing lanes to the existing two lane roadway would require either cutting into the steep up dip slope, or adding fill and expanding down slope towards the Payette river.

\section{Components of Site Investigation}

The site investigation consisted of three parts. These were as follows:

1. Field Mapping of outcrop fractures and historic landslides.

2. Soils testing.

3. Geophysical mapping of overburden and bedrock.

The geologic mapping documented the past landslides and addressed hazards related to potential rock falls. In general, hazards are greater when the fracture pattern parallels the roadway. In most cases, the joint planes mapped were suborthogonal to the roadway.

Samples for soil testing were collected by Idaho Transportation Department (ITD) during test borings and trenching activities. The borings and trenchings also provided a check on the geophysical depth determinations to bedrock. Soil testing included the following:

1. Mechanical Analysis (Grain Size)

2. Compaction (AASHTO T-99)

3. Water Content

4. Direct Shear

5. Atterberg Limits (when enough clay was present)

6. In situ compaction and unit weight (Nuclear Density tool)

The above tests, when used in conjunction with the geophysical mapping of overburden thickness, help in the evaluation of landslide hazards. Further, both geophysical mapping of soil boundaries and soils testing aid in the design of engineered structures.

The geophysical work was conducted to map the thickness of the silty sand overburden, and the subsurface elevation of the bedrock. ITD provided CAD files with survey data. The geophysical results were presented in a report with geologic cross sections, contour maps, and CAD files with contours added to the basic ITD survey. In projects like this, the geophysical results are most helpful if integrated into the CAD environment of the end user. In particular, we have found that significant effort may be required to convert coordinate systems and relate geophysical results to the roadway. That effort is well spent in terms of end user satisfaction. Figure 1 is an index map of the project generated from the CAD files. 
This is an author-produced, peer-reviewed version of this article. The final, definitive version of this document can be found online at Geotechnical Special Publication No. 113, published by the American Society of Civil Engineers. Copyright restrictions may apply. doi: 10.4133/1.2922604

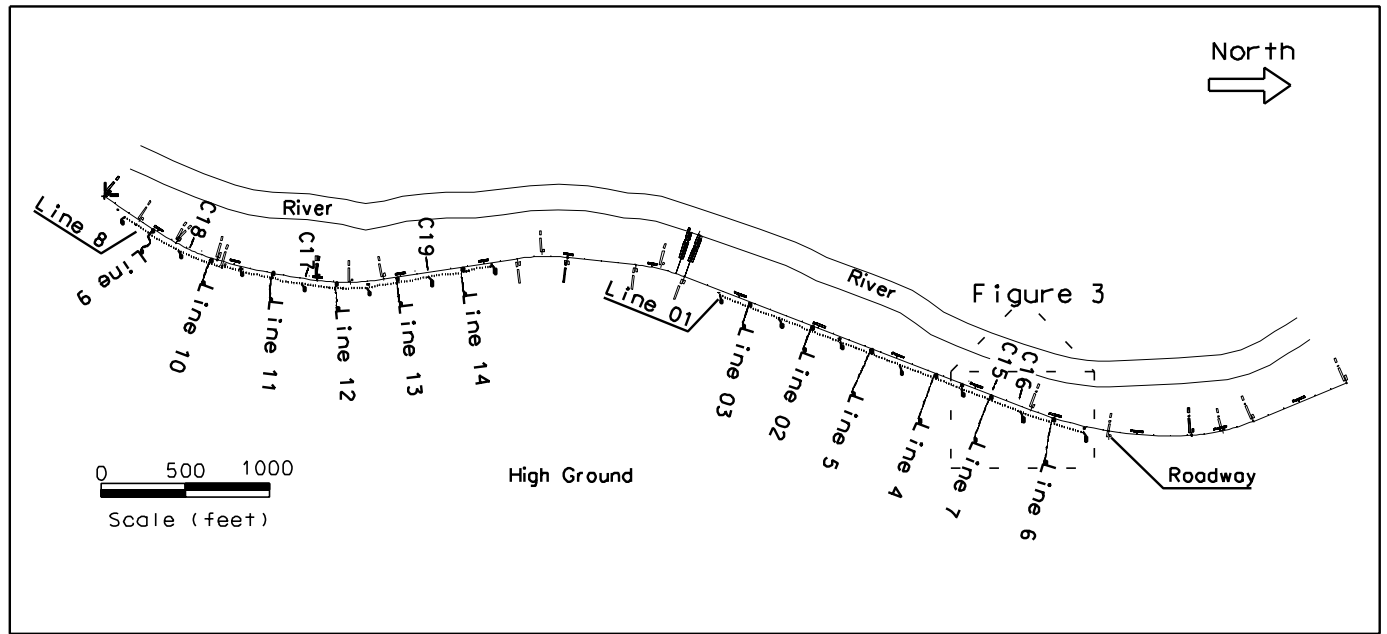

Figure 1: Base map generated from CAD file showing seismic lines and roadway survey. The river location is not surveyed in. Figure 3 is a blow up from this file.

\section{Relevance of Geophysics to Design}

When one only has surface topography and sparse outcrop control, a number of diverse geologic possibilities can be drawn. Consider the profiles shown in Figure 2. In case (A), shallow bedrock would require blasting to make room for additional lanes. In case (B), excavation without blasting would be indicated. Further, a retaining wall would be needed.

In addition to aiding engineering design, the geophysical interpretation leads to a better understanding of hazards that may exist. For example, the risk of landslides was a consideration in this project. A full analysis of landslide hazards requires evaluation of probable failure surfaces taken in the context of variable groundwater conditions. A full discussion is beyond the scope of this paper. However, one preliminary step might be to evaluate the landslide risk in terms of an infinite slope (thin overburden relative to lateral dimensions).

Such an analysis requires knowledge of the bedrock dip. That is, for a non-cohesive soil, the possible sliding of the overburden will depend on the friction angle of the sand and the dip of the bedrock. For essentially infinite slope conditions, this is expressed by a factor of safety,

$$
\mathrm{Fs}=\frac{\tan (\phi)}{\tan (\beta)} \text {, }
$$

where $\beta$ is the dip on the top of the bedrock, and $\phi$ is the internal angle of friction of the sand (Das, 1997). A factor of safety equal to unity means that failure is impending. It is desirable to have factors of safety greater than 2 , since changes in groundwater conditions and seepage can significantly alter the situation. If significant cohesion is present, that would alter the calculation. As a final caution, finite slopes require significantly more analysis than is expressed by the equation shown above. 


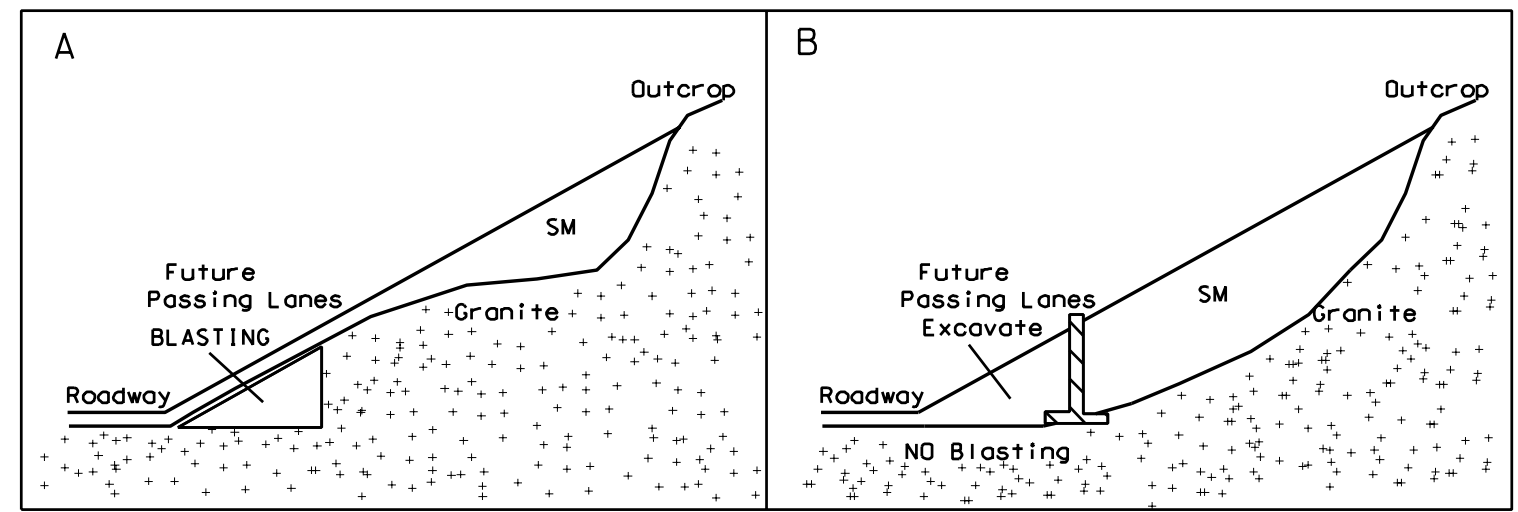

Figure 2: Two possible soil profiles for a given surface geology. A) Shallow bedrock requires blasting, (B) Thick overburden can be excavated without blasting, but a retaining wall will be needed. Refraction methods can resolve the issue in advance of construction.

\section{SOILS TESTING RESULTS}

The overburden soil was sampled at a number of locations along the approximately 6000 feet of roadway under investigation. The detail map, Figure 3, shows the location of two of the 12 trenches from which samples were collected. Presented below are results for samples taken from Trench 2 (near seismic profiles 7 and 15 ). They are representative of the overburden. Located at Sta. 581+00, two bags were collected in the depth interval from 0 to 8 feet. Figure 4 shows the grain size analysis results (Santi, 1995). Based on grain size, the soil has a Unified classification of SM (silty sand with gravel). Compaction testing determined an optimum moisture content of $10.7 \%$ and a maximum dry density of $123.4 \mathrm{lb} / \mathrm{f}^{3}$ (Santi, 1995). Samples were remolded and maximally compacted, then saturated with water and subjected to direct shear testing (shear rate of $.05 \mathrm{in} / \mathrm{min}$ ). The results were an internal angle of friction $\phi=31.5^{\circ}$ and a cohesion of $200 \mathrm{lb} / \mathrm{f}^{2}$. While this sample was nonplastic, in some cases enough clay was present for Atterberg limits testing. In those cases, a liquid limit of about LL=31\% and a plasticity index of $\mathrm{PI}=16 \%$ would be typical.

In situ nuclear density testing showed that the in place silty sand was in a less compacted state than was the case in the direct shear testing. In place soil dry densities were in the range of 94 to $118 \mathrm{lb} / \mathrm{f}^{3}$ (generally $74 \%$ to $96 \%$ of maximum). Given that the topography dipped by as much as $30^{\circ}$ from the horizontal, in place overburden was judged to be at the angle of repose.

\section{GEOPHYSICAL WORK}

With the goal of mapping the bedrock-soil interface in mind, the P-wave refraction method was selected as being most appropriate and cost effective. Of the many possible approaches (see ASTM, 1996 for example), the delay time method was chosen for the analysis. Reasons included:

1. The delay time method permits mapping of non-planar refractors.

2. The delay time method permits interpretation of the delay times as variations in either overburden velocity or spatial structure of the refractor.

3. The delay time method can be applied in 3-D. 
This is an author-produced, peer-reviewed version of this article. The final, definitive version of this document can be found online at Geotechnical Special Publication No. 113, published by the American Society of Civil Engineers. Copyright restrictions may apply. doi: 10.4133/1.2922604

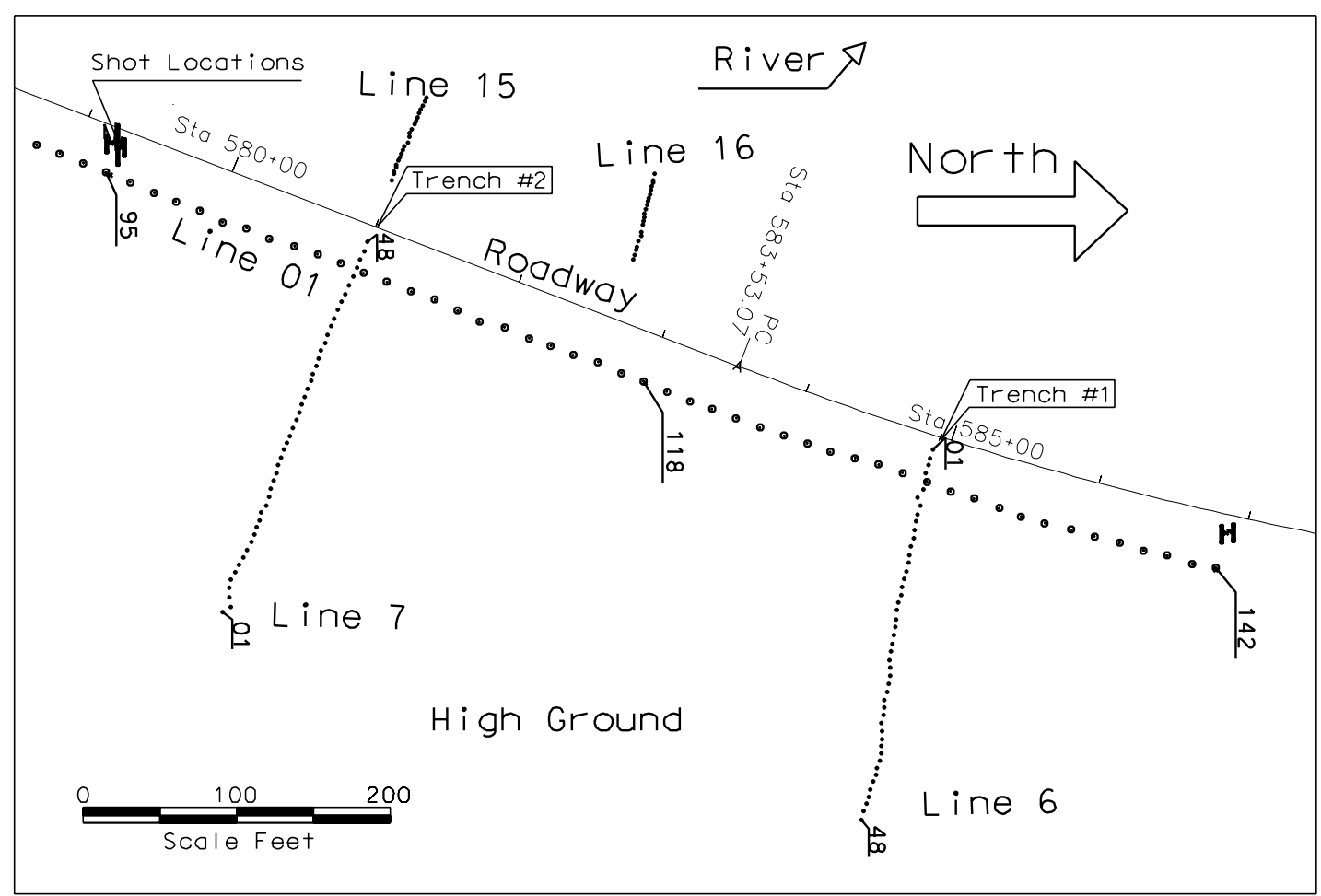

Figure 3: Detail of a portion of map shown in Figure 1. The soil samples testing presented here are from trench \#2. The geophysical derived soil profile from lines 15 and 7 will be shown in Figure 6.

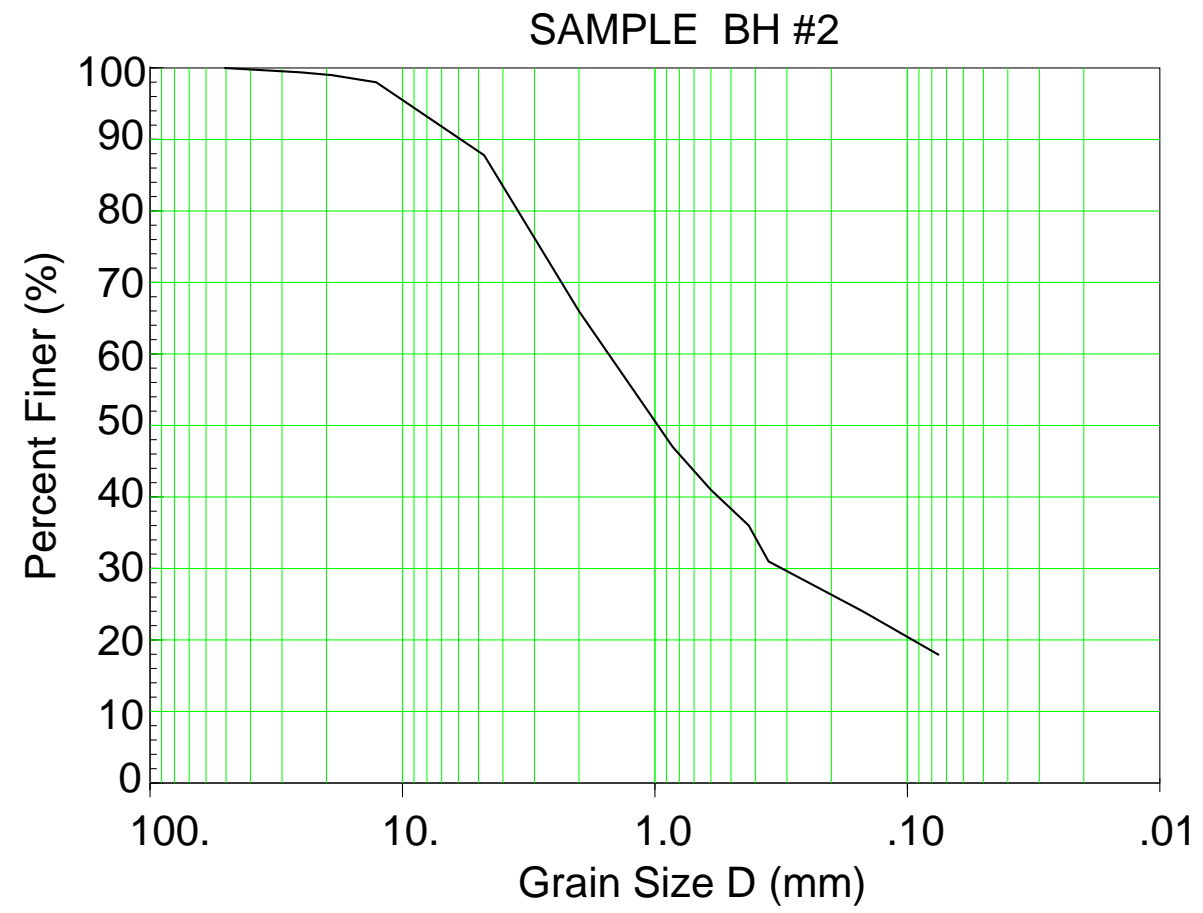

Figure 4: Grain size analysis for sample from trench \#2. The Unified classification is a SM, silty sand with gravel. The sample is $24 \%$ gravel, $70 \%$ sand, $16 \%$ fines (silt and clay). Data provided by Idaho Transportation Department (Santi, 1995). 
This is an author-produced, peer-reviewed version of this article. The final, definitive version of this document can be found online at Geotechnical Special Publication No. 113, published by the American Society of Civil Engineers. Copyright restrictions may apply. doi: 10.4133/1.2922604

This last point was critical, since the State right-of-way and topographical constraints limited the maximal offsets available in the dip direction. In other words, there was not enough space available to shoot simple refraction lines in the dip direction (since the cross-over distance was too large). To get geologic cross sections extending from the roadway, every phone needed to have a refracted first arrival in the direction orthogonal to the roadway. Thus, the 3-D acquisition consisted of two stages:

1. Base line shooting parallel to the roadway.

2. Cross line shooting, shots located broadside.

\section{Base Line Acquisition}

Base lines were programmed parallel to the roadway, offset approximately $5 \mathrm{~m}$ from the edge of the roadway. These are lines 01 and 08 in Figure 1. The lines were formed by splicing a collection of conventional reverse profiles shot with a $5 \mathrm{~m}$ geophone spacing. Single vertical component $(10 \mathrm{~Hz})$ phones recorded data from either explosive or hammer sources. Explosive sources were $1 / 3 \mathrm{lb}$ Kinestick charges buried about $1 \mathrm{~m}$. The hammer source was a $12 \mathrm{lb}$ sledge striking a 6 inch diameter metal base plate (20 fold vertical stack). The explosive data were superior, especially for the longer offsets.

The recording instrument was a Bison 9648 engineering seismograph. Filters were set to 8 and $500 \mathrm{~Hz}$ (no notch). The record length was 2000 samples, and the sample interval .00025 seconds. Instrument gain was typically $40 \mathrm{~dB}$, but often was decreased towards the source. Typically 5 shot groups of data would be inverted simultaneously by the delay time method. This would include two shots placed about $10 \mathrm{~m}$ off the end of the live spread, two shots at the end phones of the live spread, and one shot in the middle. The redundancy helped distinguish the refracted arrivals from the direct wave arrivals.

Figure 5 shows a typical shot record with a dynamite source about $9 \mathrm{~m}$ off the end of the profile. The typical cross-over distance was about $30 \mathrm{~m}$. In this figure, the first arrivals crossover from direct wave to bedrock refraction at about station 90 .

\section{Cross-Line Profiles}

Geophones were deployed with either $1 \mathrm{~m}$ or $2 \mathrm{~m}$ spacings between phones. The larger spacing was used to look further up slope. In a second phase of the shooting, cross-lines were also deployed down dip, towards the river. In some cases, two parallel down-dip lines would be shot into at the same time from a single broadside shot. Placing the shot off to the side, we were able to achieve up to $60 \mathrm{~m}$ near offset distances, resulting in refracted first arrivals on every channel (no direct wave). This permitted imaging the bedrock right up to the roadway surface. Cross-line shots reoccupied some of the base line shot positions (for which delay times would already have been determined by the base line shooting)

\section{Refraction Interpretation Method}

The specific delay time inversion method used is fully described in Michaels (1995). Additional discussion of inversion theory may be found in Menke (1984). The author began with a rather conventional set of reverse profiles ( 5 shots recorded on the same 48 channel spread of phones). The data were picked for first arrival times and examined to determine a cross-over distance. Direct arrivals from all 5 shots were simultaneously inverted in a simple least squares matrix inversion to determine the overburden velocity.

Similarly, refracted arrivals were inverted from all 5 shots at once to determine delay times at all source and receiver positions, and a single refractor velocity. The inverted delay 


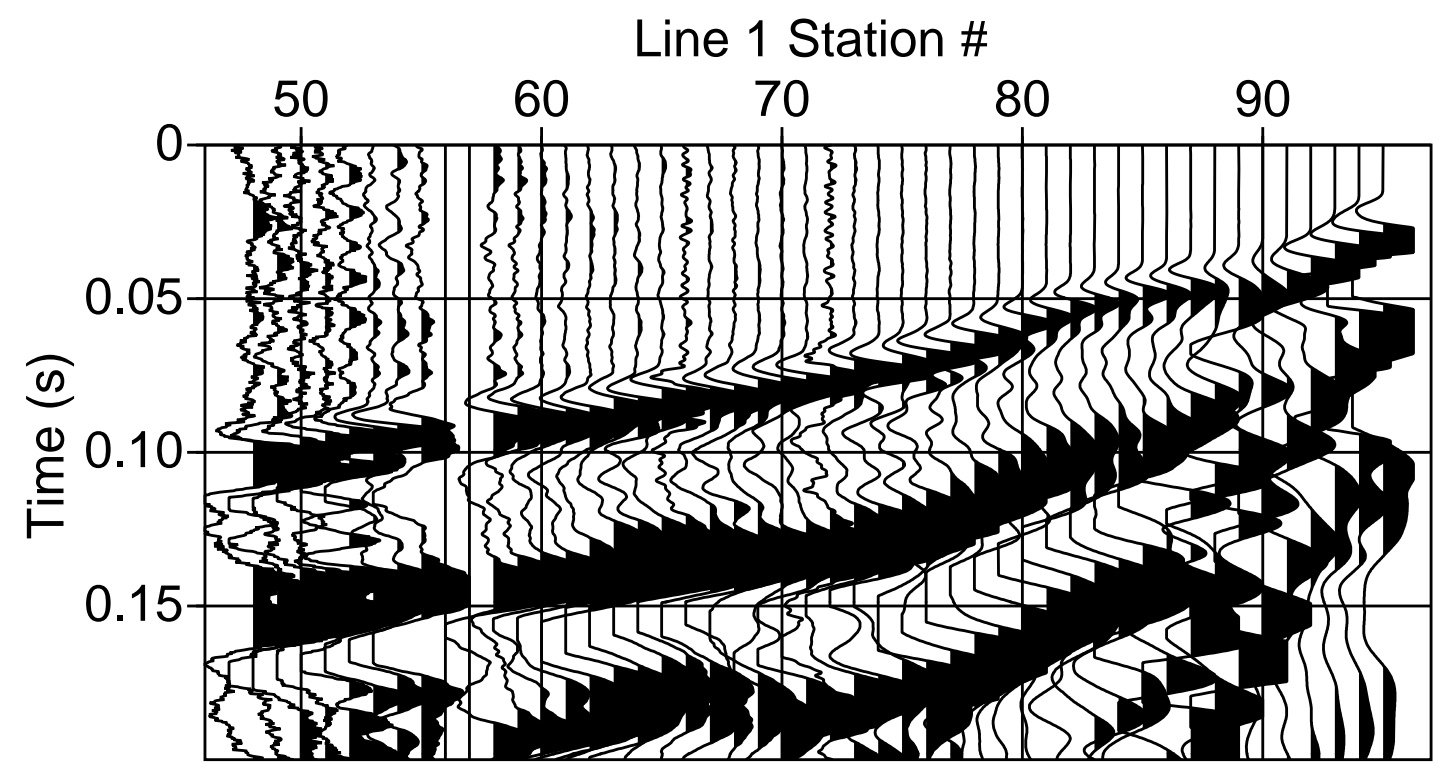

Figure 5: Typical shot record, explosive source. Shot was near station 97 (about 8.5 meters near offset). Nominal station spacing was 5 meters (measured locations surveyed with a Topcon total station). The direct wave is the first arrival on stations 95 to about 90 (30 m cross-over distance).

times, source and receiver elevations, uphole times, and direct arrival velocity information were combined to produce geologic cross-sections.

The source delay times were noted and used later to constrain the cross-line inversions (which would otherwise be posed as a singular problem). In summary, the base line shooting was used to:

1. Determine the cross-over distance and identify the refracted arrivals.

2. Determine overburden velocities.

3. Determine shot delay times.

4. Determine refractor velocities

The results from (3) and (4) were later used to constrain the cross-line inversions. That is, unique solutions for the cross line inversions were made possible by reoccupying shot locations for which source delay time solutions had already been achieved with the inline shooting.

\section{Refraction Images}

In general, the delay times are a measure of the distance between the shots or phones and the refractor in units of time. Variations in delay times can be, in the limit, attributed to either variations in overburden velocity or refractor structure (Michaels, 1995). In reality, both may be occurring. After examining the overburden excavations, direct arrivals inversions, and refractor velocity inversions, the author concluded that constant average velocities could be used for both the overburden and the refractor. The delay times were then attributed entirely as structure on the refractor. Space permits only a small sample of the many cross-sections determined to be shown here. The many cross-sections produced were then used to construct contour maps of the overburden thickness and buried bedrock topography. 


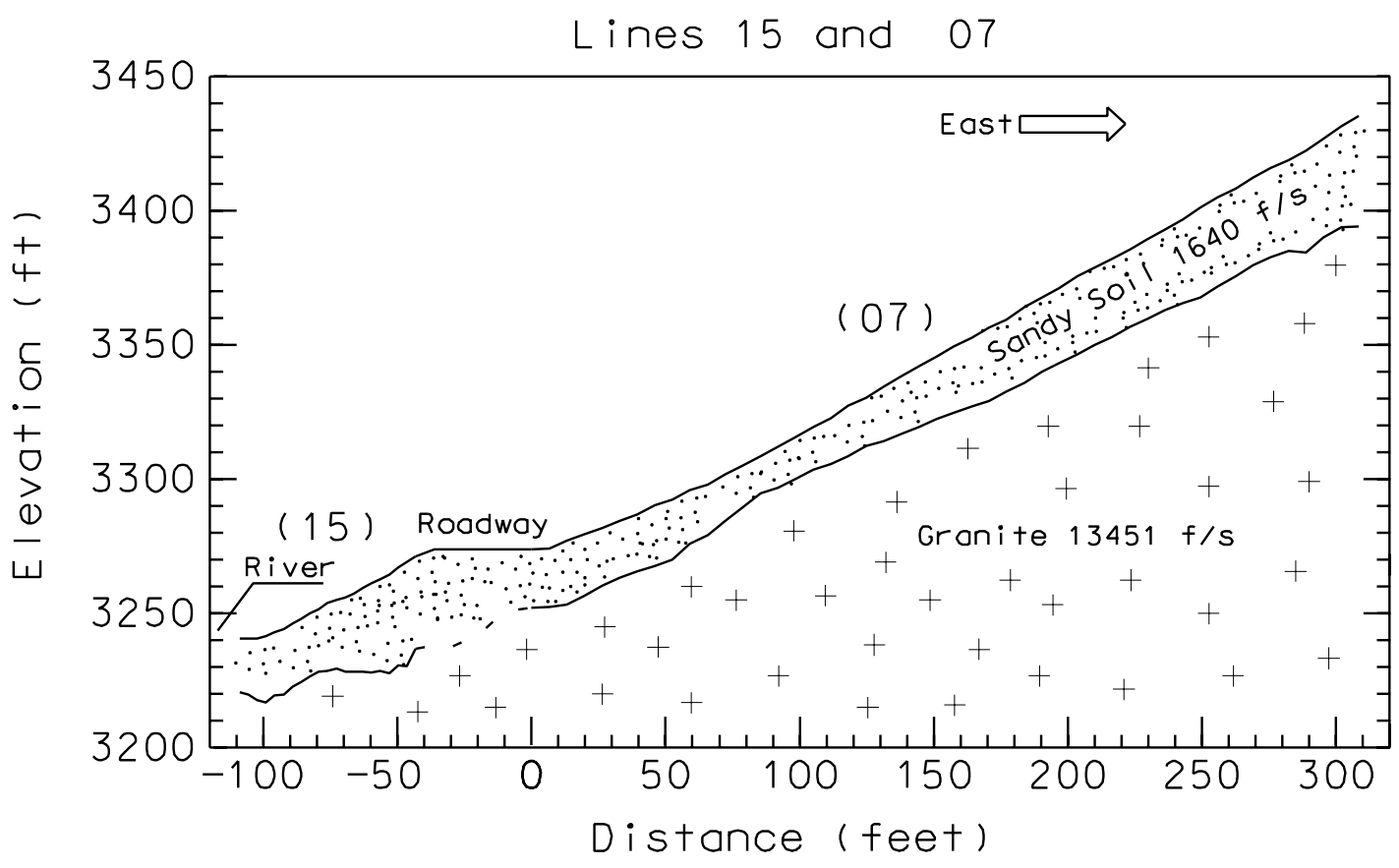

Figure 6: The combined solutions for profiles 15 and 07. Since traffic was too heavy to place geophones on the roadway, no refraction results could be obtained directly under the pavement. Trenching on the east side of the roadway did not reach bedrock, but was terminated at a depth of 15 feet in gravels with sand and boulders (some larger than 7 feet in diameter).

Figure 6 shows the combined results from two cross-line profiles (07 and 15). These two profiles were in alignment and on opposite sides of the roadway. They also are at the position of Trench \#2 (see soil analysis results shown above).

Initially, it was expected that only a few feet of overburden existed, with bedrock being shallow. Trenching efforts at $\mathrm{BH} \# 2$ failed to reach bedrock at the maximum excavation depth of about 15 feet (Nottingham, 1995). The water level was at a depth of about 14 feet. As can be seen in Figure 6, as much as 40 feet, and as little as 15 feet of silty sand overburden exists along this profile. It appears that some fill had been added to provide a level roadway. Furthermore, bedrock dips vary from $25^{\circ}$ to more than $30^{\circ}$ (exceeding some measures of the friction angle for the soil). The up dip soil surface appears to be nearly at the angle of repose. In general, the risk of future landslides at this location is significant, and could occur with changes in the groundwater conditions.

\section{SUMMARY}

In conclusion, the mapping of bedrock and overburden thickness right up to the roadway was made possible by using a 3-D variation on the delay time method. The resulting geologic cross-sections, when combined with the soils testing and trenching provide a picture which was not entirely expected. The differing site conditions included a thicker than expected overburden layer which posed significant risk of landslides, and would have required a more expensive 
This is an author-produced, peer-reviewed version of this article. The final, definitive version of this document can be found online at Geotechnical Special Publication No. 113, published by the American Society of Civil Engineers. Copyright restrictions may apply. doi: 10.4133/1.2922604

design than was originally estimated. The blasting that would be required in the middle of the project (where granite is exposed), combined with the thick overburden over the rest of the project significantly impacted the economics of the project. Rather than proceed with the passing lanes at this location, ITD decided to look for a more favorable location.

\section{ACKNOWLEDGMENTS}

The author wishes to acknowledge Dr. M. Dougherty who collected a large portion of the data and directed much of the field operations. Thanks also go to the Boise State University students who helped collect the data as part of their educational experience. Finally, the author thanks the Idaho Transportation Department for providing a project in which students could gain practical field experience in engineering geophysics. Further, ITD generously provided the author access to soil testing results for preparation of this paper. Display of the seismic data was done with Seismic Unix running on a PC in the Linux operating system. Word processing was done with RedHat Applixware. No Microsoft products were used in preparing this report. CGISS contribution number 0082

\section{REFERENCES}

ASTM, 1996, "D5777-95: Standard guide for using the seismic refraction method for subsurface investigation", in American Society for Testing and Materials, 1996, "Annual Book of ASTM Standards", Section 4, Construction, Vol. 4.08 Soil and Rock (I): D420-D4914 ASTM,West Conshohocken, $\mathrm{Pa}, \mathrm{p}$, 556-568.

Austin, T., 1994, "Geotechnical Baseline Reports", Civil Engineering, Vol. 64, No. 12, pp.56-57

Das, B.M., 1997, Principles of Geotechnical Engineering, 4th ed., PWS Pub. Co., Boston, Ma $572 \mathrm{p}$.

Menke, W., 1984, Geophysical Data Analysis: Discrete Inverse Theory in International Geophysics Series, Vol. 45, Academic Press, San Diego, CA 289 p.

Michaels, P., 1995, "A geophysical site investigation for a bridge foundation in a narrow canyon", Environmental \& Engineering Geoscience, Vol. 1, No. 2, p. 219-226.

Nottingham, K., (1995), "Foundation and slope stability exploration field log, Sta. 581+00.24'R+CL, BH\#2", Idaho Transportation Dept., Key no. 5648, Project ST-3270(606)

Santi, M., 1995, "Report of tests on soil, station 581+00, BH\#2, depth 0-8ft", Idaho Transportation Department, Key no. 5648, Project ST-3270(606).

Steigler, M.H., 1994a, "Unforeseen conditions don’t break fix costs", Civil Engineering, Vol. 64, No. 3, p. 27.

Steigler, M.H., 1994b, "Geotech surprises should be expected", Civil Engineering, Vol. 64, No. 12 , p.24. 